\title{
Approaches to the Evaluation of Teaching and Learning Methods at a University: Evidence from South Africa
}

\author{
Gumbo JR
}

\begin{abstract}
An increasing number of students drop out of university in South Africa and throughout the world. The South African Council for Higher Education has introduced strategies to deal with high dropout rates, which include the improvement of teaching and learning through the Quality Enhancement Program. I hereby document and evaluate my teaching and learning methods. The data collection for this research involved student informal evaluation, formal evaluation and peer evaluation. The formative evaluation data was grouped in 14 themes with numbers in brackets representing the number of counts of student expression of [their free form]: good lecturer (51); stop pointing (12); request for softcopy of lecture notes (7); speak with a loud voice (5); time to write notes (4); field work/practicals (2); do not understand lecture notes (2); lecturer coming late (2); lots of lectures notes and case studies are long (2); update notes (1); no double class on Friday (1); timetables are clashing (1); require a small tests (1); revision of lecture (1). The concerns for summative evaluation were: I was a good lecturer; issues on hard copies of lecture notes and feedback on assignments. With regard to peer evaluation, a fellow academic attended one of my lectures to make observations and review the teaching and learning procedures. I was able to observe that I ended my lectures too abruptly. As a result, the suggested approach was that gradually end the lectures with a series of questions that invoke a critical response from students and ask any student to summarize the lecture in three sentences. I have since implemented the student concerns.
\end{abstract}

Keywords - student feedback; summative and formative; higher education; student evaluation; university drop-out rates; improved quality teaching and learning methods.

\section{INTRODUCTION}

The Council for Higher Education (CHE) is the legal custodian for quality assurance of teaching and learning at institutions of higher learning in South Africa as per the Higher Education Act 101 of 1997 [1]. A permanent sub-committee, the Higher Education Quality Committee (HEQC), is however, responsible for the implementation of national policy on quality assurance [2-3]. The University of Venda (Univen) introduced the 'Monitoring and Evaluation of Teaching \& Learning Policy' in 2008 [4] which sought to 'uphold the values and practices of constructive feedback, self-evaluation, and peer review and ethical professional conduct' and this is achieved through 'systematic approach to Monitoring and Evaluation of teaching

J.R. Gumbo is with the University of Venda, Department of Hydrology \& Water Resources (e-mail: jabulani_gumbo@yahoo.co.uk; jabulani.gumbo@univen.ac.za). and learning'. The intention of the policy, therefore, is , as echoed in the Rhodes University, policy perspective, to promote 'good teaching' and encourage staff to engage in a process of reflective practice [5].

As a university lecturer, I constantly reflect on my teaching and learning activities (TLA) and consider how best I can improve the teacher and student interactions. In this discussion I define the evaluation of my teaching methods and illustrate how I have embedded evaluation in my teaching and learning processes. I also review the national and institutional quality imperatives and fundamental theories of evaluation that underpin teaching and learning. Lastly, I discuss the ethics of student and peer evaluation and how ethics can contribute to a 'better' evaluation and use of the outcomes for developmental purposes.

\section{A. National Arrangement for Quality Assurance in South Africa}

The CHE through the HEQC implements the quality assurance process at Universities in South Africa. The functions of HEQC [3] are as follows:

The mandate of the HEQC includes quality promotion, institutional audit and programme accreditation. As part of the task of building an effective national quality assurance system, the HEQC has also included capacity development and training as a critical component of its programme of activities.

And the HEQC [3] institutional focuses are:

-Quality assurance - the policies, systems, strategies and resources used by the institution to satisfy itself that its quality requirements and standards are being met;

-Quality support - the policies, systems, strategies and resources used by the institution to support and sustain existing levels of quality;

-Quality development and enhancement - the policies, systems, strategies and resources used by the institution to develop and enhance quality; and

-Quality monitoring - the policies, systems, strategies and resources used by the institution to monitor, evaluate and act on quality issues.

Earlier on, a South African study by [6] showed a low graduation percentage of $30 \%$ of students' first entering university. Hence, this observation spurred the $\mathrm{CHE}$ to introduce Quality Enhancement Project (QEP) in order to 'enhance student learning with a view to increasing the number 
of graduates with attributes that are personally, professionally and socially valuable' [1].

The Council of Higher Education [7] completed an audit in 2010 of the University of Venda as part of its mandate. The HEQC made the following recommendation 'the University of Venda address the conceptualisation of planning and quality underpinning the work of the Institutional Planning and Quality Assurance Directorate, including the technical and human resources available to it, in order to ensure that the responsible staff have sufficient knowledge, training, capacity and seniority to interact appropriately with senior academics to discharge their responsibilities.' As a result, a number of other staff members and I enrolled at Rhodes University to study for a postgraduate diploma in Higher Education in an effort to improve my approaches to Teaching and Learning.

\section{B. Institutional Arrangements of Quality Assurance at University of Venda}

The Department of Institutional Planning \& Quality Assurance (IPQA) at Univen is responsible for internal quality assurance of elements such as the quality of teaching and learning. The functions of IPQA [8] include 'Receiv[ing] and respond[ing] to peer, expert and student feedback on the quality of programmes and courses and Assur[ing] the University Council, Vice-Chancellor and other interested parties of the high standards and overall quality and soundness of the University's programmes and courses'.

In addition, the Deans and Heads of Departments are responsible for the implementation and monitoring of the evaluation of teaching and learning. The lecturer must actual carry out the evaluation of teaching and learning in consultation with the Centre for Higher Education, Teaching and Learning (CHETL). I have, in consideration of this, implemented the student evaluation exercise at the end of the semester.

\section{Overview of Evaluation Philosophy}

According to Ramsden [9] 'evaluation is a means of understanding the effects of our teaching on students' learning. It implies collecting information about our work, interpreting the information, and making judgments about which actions should be taken to improve practice. To reflect on what helps students to understand a concept or argument, and to apply the results to teaching, is to engage in evaluation. 'I do concur with the above arguments of Ramsden on constantly evaluation of one's teaching and learning method as this is part of reflective practice.

The evaluation cycle is composed of a number of elements such as decision on what aspects of the teaching and learning approach require evaluation, planning on the methods of data collection; data interpretation; reflectivity and implementing the changes [10-11](Figure 1). Thus, the teaching and learning approach means the students may make an evaluation the teaching methods and or evaluate the curriculum. As a result, my keenness to improve the teaching and learning methods, the focus of this paper considers the student evaluation of my teaching methods and its effect on their learning processes.

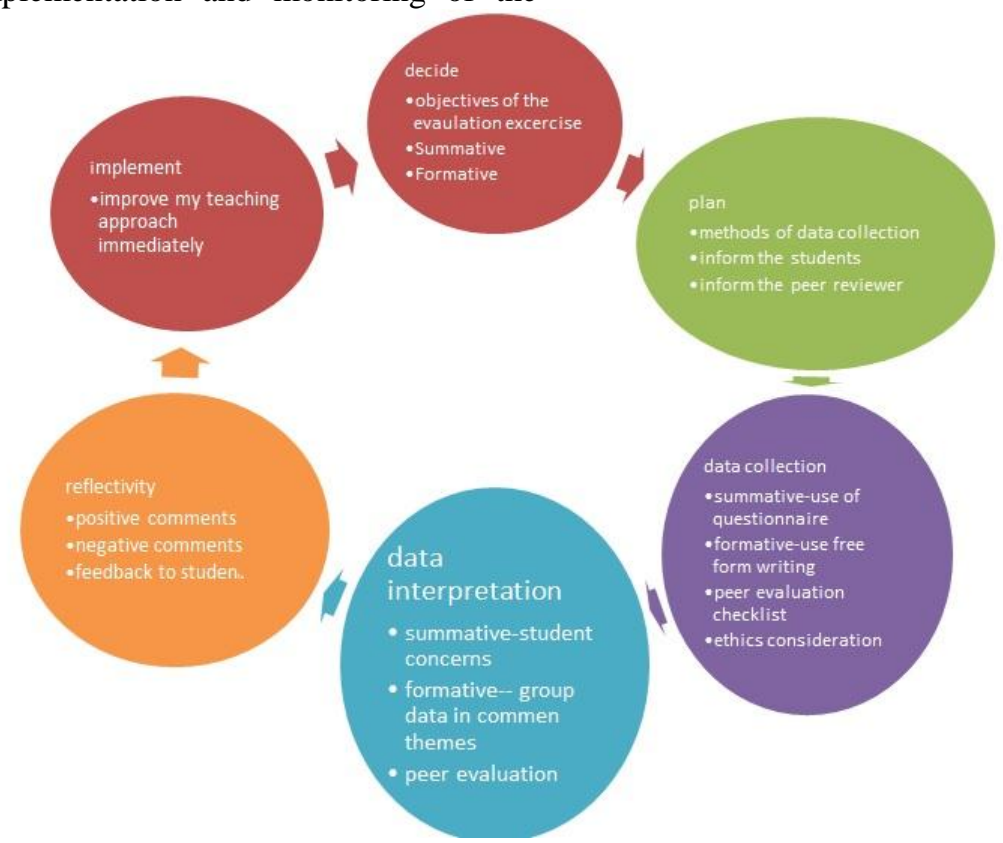

Fig 1: The interconnectedness of the evaluation cycle

Two models of evaluation have been developed by Boughey [12] and these are policing model and developmental and learning model. In the policing model, evaluation is summative and judgemental, as it is based on a set criterion. The focus is on administration of teaching and learning. The policing model is linked to issues of promotion and tenure. The student evaluation associated with this model then, is summative and involves the students completing questionnaires at the end of the semester.
Thus, any feedback (outcome) of the student evaluation exercise is used to improve the teaching method for the students of the following year. At my University of Venda, the policing model is the predominate form.

Biggs [13] notes that the use of student evaluation or student feedback questionnaires demands that one be cautious because a good teacher that uses the problem based learning method can be penalized or receive a low rating from the students. This is 
due to use of 'standard questions across all courses, where the lecture is assumed to be the norm. Ratings then vary according to students' own conceptions of teaching, and penalize teachers using other methods.' As a result, there is a need to develop questions in consultation with the lecturer under evaluation, to improve validity, and for the policing model to be effective. The Centre for Higher Education Research, Teaching and Learning (CHERTL) has developed a web based software tool, Evaluation Assistant, and a set of excellent questions in which the lecturers can choose questions in consultation with CHERTL [14]. The philosophy here is to avoid tensions between the lecturer and the university management in the police model since a negative student evaluation may be used against the lecturer.

There also exists a development and learning model which is formative and developed focused [12]. The form of student evaluation here is a mixture of formal and informal evaluation methods. In the informal student evaluation method, the students write freeform and small group instructional diagnosis (SGID) [5]. Here the feedback is almost immediate in that you obtain the feedback after the students have completed writing the free-forms. The feedback is then used constructively to improve and enhance the teaching and learning method as the semester progresses rather wait for the semester to end. I therefore, prefer the developmental and learning model as this is student centered.

I am practicing both the summative and formative evaluation techniques at the University of Venda. The two techniques are complimentary as stated by Biggs [13], seeks to improve both policing and developmental evaluation models 'how the two sets of priorities are balanced is what separates a quality from a mediocre institution, a quality institution preferring to be biased towards establishing the optimal conditions for learning, a mediocre one towards administrative convenience.' This is followed by my attempts at closing the loop is important after collecting the data-student evaluation. This involves an interpretation and analysis of the students' views and perceptions on my teaching and learning methods. After decoding the data, the next exercise is to communicate to the students and show how the teaching and learning methods will be enhanced in light of the findings. Thus the purpose of this study was on the student evaluation (informal and formal) and peer evaluation of my teaching and learning methods. This was carried out in order to improve and find innovative ways of motivating the students to attend lectures.

\section{MATERIALS AND METHODS}

\section{A. Students' Evaluation}

The methods used in data collection involved asking to HWR2541 students during a lecture to stop for moment and write in free form what they thought of my teaching and learning methods (informal evaluation). The notes were collected and then grouped into themes for further analysis. Then at the end of the semester, the same students were given a questionnaire developed by CHETL to evaluate the teaching and learning methods (formal evaluation).

\section{B. Peer Informal Evaluation of My Teaching Methods}

Here I asked a fellow staff member from another department to come and sit in my lecture. The staff member then compiled a report about my teaching and learning methods.

\section{Ethical Considerations}

The students were asked NOT to write their names nor student identity numbers in an effort to consider the ethics in the formulation of the informal student evaluation. I also informed the students that their comments may be used for research purposes, as in this paper, and received signatures of consent. The emphasis on student removal of any identifiers during the informal evaluation assisted with removal of biasness. However, the validity of their responses may be a big challenge. Thus, in future I must request an external person to conduct the informal student evaluation in order to improve the validity and biasness of the evaluation. The same should also happen with the closing the loop and data analysis; I will request an external person to carry out the exercise. The issue of closing the loop is important as it leads to the enhancement of student learning [15-16]. This will ensure that an authentic report is made and also assist me when writing a response to the issues raised by the students.

\section{RESULTS AND DISCUSSION}

\section{A. My Current Evaluation Practices}

According to Ramsden [9] a good teacher is always evaluating oneself and aware that 'evaluation is best conceptualized not as something that is done to teachers by experts wielding questionnaires and computers, but as something that is done by teachers for the benefit of their professional competence and their students' understanding. Evaluating teaching concerns learning to teach better and exercising control over the process of learning to teach better.' This view by Ramsden [9], which agree with, underscores the need for constantly evaluation of one's teaching and learning method and thus ties in with the reflective practice that is fundamental to my self-evaluation.

There are however, a number of evaluation methods that students can use to solicit views about my teaching and learning methods. These include, filling a questionnaire, focus group discussions, free form writing, using concept maps, making critical learning statements and engaging in class room critical incident questionnaire. The most common method is the online and offline questionnaire and paper based questionnaire. At the University of Venda, the paper-based questionnaire form is the widely used method, as shown in the study by Makondo and Ndebele [17]. Nevertheless, the use of long standard closed questionnaires has many drawbacks such as providing very little and generalized information and the possibility that students may suffer questionnaire fatigue [5]. The questionnaire is the method of choice in gathering feedback from students for large classes. However for small classes, the small group instructional diagnosis is recommended [5]. I practice free form exercise (formative evaluation) and questionnaire (summative evaluation) and I will discuss these further below, while drawing on the University of Fort Hare's [18] policy on teaching and learning. 


\section{B. Student Formal Evaluation of My Teaching Methods and Responses}

The formal student evaluation uses the questionnaire and an informal student evaluation that is a free form of writing. At the end of the semester period, I hand out the Students' Evaluation of Teaching Instrument that was developed by the Centre for Higher Education Training and Learning (CHETL). The students proceed to complete the form and I then submit the completed forms to CHETL for analysis and report writing.

Due to staffing challenges, CHETL has been unable to administer the student evaluation to ensure validity of the outcome or carry out analysis on time. This external person other than me will ensure that the outcome is valid and the students are not biased. Secondly the standard evaluation questionnaire is completed by the whole University of Venda regardless on the school or academic discipline. As Biggs [13] stated, the outcomes may be biased such that the students may grade the lecturer lower during the use of the standard questionnaire. Hence, I will assign an external person to administer the questionnaire to the students in future (end of this semester to improve on the validity of student evaluation.

The main points that were raised by the students' evaluation were: I was a good lecturer; [issues on hard copies of lecture notes and feedback on assignments]. I responded to the student evaluation report by releasing hard copies of lecture notes on a regular basis. I used to issue out hard out copies of lecture notes at the start of the semester, but had noticed that the lecture attendance dropped and the students would on attend lectures during sessions where assignments were being handed in. The module HWR 2541 Rural Water Supply and Sanitation is a second year service module taken by all second year students in the School of Environmental Sciences and usually has between 240 and 300 registered students. Thus, in the years following the student evaluation, I have decided that I will not give out lecture notes at the start so as to encourage lecture attendance. These lecture notes were then given out at regular basis, following the completion of a topic. The second issue from the student evaluation assessment report related to regular feedback on the assignment. This is a big challenge as I was teaching a large class, as a result, it would take a month to mark an assignment and during that year I was teaching three modules in each semester. However, my enrolment for a Post Graduate Diploma in Higher Education at Rhodes University has been an eye opener. I was able to acquire skills on how to effectively teach large classes and marking assignments faster through means such as peer assessment.

\section{Student Informal Evaluation of Teaching Methods and My Response}

As a way of obtaining immediate student evaluation of my teaching and learning methods, I requested the students to write short pieces about my teaching methods. Prior to this, I has spent some time explaining the process and emphasized on their anonymity through not writing their names or student numbers on the paper. The feedback that I received was interesting. The analysis was broken down into 14 themes: speak with a loud voice (5); stop pointing (12); timetables are clashing (1); good lecturer (51); field work/practicals (2); update notes (1); no double class on Friday (1); do not understand lecture notes (2); require a small tests (1); lots of lectures notes and case studies are long (2); request for softcopies of lecture notes (7); revision of lecture (1); lecturer coming late (2) and time to write notes (4). The numbers in brackets represent the number of counts of student expressing the free form.

I noted some of the outcomes and have begun implementing them, as discussed below. For instance, the student stated that 'in terms of lecturing you bare too good but my only concern is that you are too soft when you are lecturing and some they don't even hear and understand what you are saying'. I have tried to speak louder in class and I have requested students at the back to raise their hands if my voice is low. I have also written submissions to Facilities Management requesting communication technologies and devices to cater for large lecture theatres such as the University of Venda's E-block, to enhance the reach of my lecture to all students.

The [stop pointing] is interesting in that the lectures are 50 minutes. I teach for 45 minutes with a regular pose for questions from myself and or from the students. The other part of the 5 minutes caters for 2 or 3 students who I always ask to summarize what we would have learnt on that particular day. This last part of the lecture allows me to pose a question and compel the students to engage in reflective learning on the material covered that day. Secondly the students I request to summarize are selected at random. Felder and Brent [19] said that this direct pose will ensure that the students learn something and that anyone can be expected to answer the question. Thus, I remove the comfort zone and make sure that the students that come to the lecture are able to participate in the discussion. However, I have noticed that some of the students that I select seem to have a challenge in the use of English language speaking, 'but not all of us a good at talking, some prefer writing'. Another student pointed out that this was good 'after his teaching he recommends us to summarize what we learnt about which is a good idea for us as students to understand.' Another student wrote 'the fact that he asks for a summary after a lesson makes use focused hen is lecturing,' in support the idea of summarizing.

The issue of timetable clashes is usually caused by third or fourth year students that would be attending a second year module. One student wrote: 'on Friday I have clashes from 12 to 1:00pm. So you can help me by organizing a class early for the people who have clashes because I miss so much and it will not do any good to me'. Another student did not like Friday lectures, as noted in the statement that, 'please I don't like it for double class on Friday. Can we please postpone it to next year'? Interestingly, this module HWR 2541 Rural Water Supply and Sanitation, is, as already noted, a service module taken by all second year students in the School of Environmental Sciences. Thus, there is need to ensure that no third or fourth year students are registered for a second year module, to avoid clashes.

A majority of feedback stated that I was a good teacher. One student stated that 'I love/like attending your class because I understand what is displayed on the slides through your voice, questions you raise in class, how you explain and your videos which I sometimes call them movies.' Another student wrote 
that 'your method of teaching is very good because you use examples which are relevant to what we go through in our everyday lives. You use videos which are happening in reality. Every day after lesson you try to get a summary from students to find out if we understand what you taught' and 'make full use of the 50 minutes lecture time. He is audible enough and allows students to ask questions as well as gives them (students) a time to reflect on the lesson'. This last quote from the student is important in that it internalize the teaching and underscores that the students actively take part in their learning. Another student drew on my teaching methods to support the view that I am good teacher as noted in the statement that, "the method of teaching you are using is very good, up to date, clear and understandable. The methods include discussions in class, writing and explaining the slides, watching videos and getting the assignments on library catalogue. These methods improve our learning skill and we also grow academically'.

The module HWR 2541 Rural Water Supply and Sanitation has a component for field work. The students here confirmed how the lecture method is enhanced by the practicals and noted in one statement that, 'actually you are doing your best in teaching and we are learning a lot. Learning aspects need improvements on doing maybe practical teaching because other things need experiments so that we will understand better' and 'we need field trip to dam and water treatment plant.' In support of the student view here, I planned two trips, one to field station at Mhinga where there are three boreholes with monitoring equipment this semester (2015). The Mhinga field visit was undertaken on 23 April, 2015. The other trip was to a factory that manufactures ceramic water filters used in reducing microbial contamination of drinking water in rural areas (2016).

Another student also requested that 'update your notes its 2015'. Nevertheless, the notes on the HWR 2541 Rural Water Supply and Sanitation module are constantly being updated. There is, therefore, an on-going exercise in obtaining new case studies and new videos from www.youtube.com to enhance teaching and learning.

There are some students who stated that they did not understand the lecture notes. One student wrote, 'you teach very well, the only problem is that I don't understand your lecture notes is not understandable'. To assist these students I have decided to use a language that is accessible in my lectures. I have also asked the students to buy an English dictionary in order to improve the understanding of the certain words. In addition, the use of videos from www.youtube.com, on topics such as bilharzia (schistomiasis) infection, its impacts and symptoms, assists in explaining, demonstrating and making the students visualize the issues under study.

Spot tests ensure that the students come to every lecture if these tests contribute to overall semester mark. One student wrote that "please try to give use some small tests at the end of each chapter, it will help us a lot in knowing how you ask questions and even the structure of the question paper. Even the take home test in fine'. In concurrence with the student, I introduced the 5 minute tests in the second half of this semester. At the same time, I have introduced student (peer) assessment during the course of this semester with good results. This peer assessment will be discussed in the module 3: Assessment. Thus the short tests will be marked by the students after a discussion on the assessment criteria.

There were other student complaints that seemed frivolous. One student complained about the huge amount of lecture notes. Another complained about assignments on problem based learning or case studies. The student wrote 'I am enjoying your lectures, but there is one thing bothering me. Your case studies are too long. I spend too much time reading'. This is quite ironic, but I hasten to point out that if the students spend time reading and hopefully understanding the case studies then I will continue with this kind of teaching methods.

A number of students stated that they wanted soft copies of the lecture notes. Some of them wrote 'students have to take notes while listening so I am suggesting that due to the improvement of our university (tablets) it will be better for students to have soft copies so that their notebook will be used for summarizing most highlighted points'. One echoed the same sentiments 'the problem is that some of us as students its difficult for us to write while listening as he does not provide with slides. If possible may you please provide us with slides so that we can be able to understand your lesson very well'. In addition, another suggested that they be provided with the notes beforehand so that they can study and improve on their class participation. The student wrote, 'I think it would be best if we as students get notes so that we can study before lectures then we can ask questions in class'. The University of Venda has issued tablets to all second year students and this has improved my work too. I do concur with the students that I must provide them with soft copies of the lecture notes. I must find ways of uploading the lecture notes on the Univen website where the students can then download onto their tablets.

Another student pointed out that I must revise the previous lecture before commencing on a new one. The student noted that 'in every lecture he tries his best that all students are covered and understand what's its being touched. The problem I have with him is that he does not do revision and he gives a lecture today, tomorrow we can move on'. Though I revise the previous lecture with students, I will inform the class about the connection between a current lecture and previous one.

Some students complained that I come to the lecture late. One student wrote that 'your teaching is far much better but the problem is that at sometimes you come to class late and by coming to the class late we end up not finishing the work of the day'. I do concur with the student, however this usually arise from time spent in search of the mobile overhead projector and or the extension cables, as the overhead projector in lecture theatres are malfunctioning. I have even purchased my own extension cable but it got lost. However, I have resolved to improve on the availability of a projector before the lecture commences by borrowing from other departments.

The students also stated that they wanted more time to write the lecture notes and time to listen I while lecture. One student wrote that, "he should wait for us to finish coping notes and then explain because we cannot write while in the other hand we are listening whatever he is saying. He must explain after all students finish to copy the lecture notes'. In an effort to comply with this valid request, I am now allowing more time for the 
students to write the lecture notes. Furthermore, the situation can also be improved by giving out the soft copies since all students as they now have tablets.

Therefore, the informal student evaluation provided a lot of feedback about my teaching methods in comparison with the formal student evaluation. However, the feedback from both student evaluations will greatly assist me in improving the teaching methods [20].

\section{Peer Informal Evaluation of My Teaching Methods}

In the metacognition process, I need to explore how fellow lecturers from other discourses can attend my lectures in order to peer observe how I teach and what I teach so as to elicit their critical thoughts [21]. I have asked a colleague, from the School of Education, to attend to one my lecture and the valuable information I received indicate that I ended my lectures too abruptly. The suggested approach was that I gradually end the class with a series of questions that invoke a critical response from students and to ask any student to summarize the lecture in three sentences. This approach has greatly improved my teaching methods. This is illustrated by some student responses that supported the summary issue on the grounds that it assisted them to stay focused. Some students still complained and were not interested in the gradual end with questions. Nonetheless, I intend to expand this experiment by inviting colleagues from the school to attend other lectures, peers evaluate and suggest how I can improve my teaching and learning methods.

\section{CONCLUSION}

The article considers the student and peer evaluation of my teaching and learning methods of the module HWR 2541 Rural Water Supply and Sanitation, drawing on the theories about evaluation. The data that was generated with due consideration of ethics assisted me to close the loop by preparing a detailed report on issues raised and to indicate how I intend moving forward in improving student learning. The triangulation of data and integration of ideas and norms has ensured that all aspects of evaluation are covered and national and institutional opportunities and challenges have examined in detail.

\section{ACKNOWLEDGMENT}

The author was provided with a scholarship to undertake post graduate diploma in Higher Education at Rhodes University by the University of Venda, Teaching and Development Grant 0791.

\section{REFERENCES}

[1] CHE, (2014). Framework for Institutional Quality Enhancement Project

[2] Higher Education Quality Committee, (2004a). Criteria for Programme Accreditation. Pretoria: Council on Higher Education.

[3] Higher Education Quality Committee, (2004b). Criteria for Institutional Audits. Pretoria: Council on Higher Education.

[4] University of Venda (Univen) (2012). Monitoring and evaluation of teaching \& learning policy

http://www.univen.ac.za/docs/UnivenStratDoc2012New_Lowres.pdf(ret rieved on 11/10/2015)

[5] Rhodes University, (2015a). A brief Guide to The Evaluation of Teaching and Courses. Centre for Higher Education Research, Teaching and Learning.

[6] Scott I, Yeld N, Hendry, J. (2007). Higher Education Monitor No 6: A Case for Improving Teaching and Learning in South African Higher Education. Research Paper prepared for the Council on Higher
Education by the Centre for Higher Education Development. Cape Town: University of Cape Town

[7] CHE, (2011). Audit Report http://www.che.ac.za/sites/default/files/institutional_audits/institutional _audits_2010_uv_executive_summary.pdf(retrieved on 11/10/2015)

[8] University of Venda (Univen) (2008). Monitoring and evaluation of teaching \& learning policy

[9] Ramsden, P. (1992). Learning to teach in Higher Education. London: Routledge.

[10] Bowie, C. (no date). Designing Evaluation for Improving Teaching and Student Learning https://www.griffith.edu.au/ data/assets/pdf_file/0017/119006/GPG-de v.pdf(retrieved on 11/10/2015)

[11] Rhodes University, (2015b). Tensions in evaluation

[12] Boughey, C. (2001). Evaluation as a means of assuring quality in teaching and learning: Policing or development? In Otaala, B. and Opali, F. (Eds.), Teach your Very Best: Selected Proceedings of a Regional Conference for Staff from Tertiary Institutions from SADCC Countries (pp. 18-29). Safari Court and Conference Centre, Windhoek, Namibia, 1-3 October, 2001

[13] Biggs, J. (2001). The reflective institution: Assuring and enhancing the quality of teaching and learning. Higher Education 41: 221-238, 2001.

[14] Rhodes University, (2004). A brief Guide to using the Evaluation Assistant.

[15] Powney, J., \& Hall, S. (1998). Closing the loop: the impact of student feedback on students' subsequent learning. Edinburgh: Scottish Council for Research in Education

[16] Watson, S. (2003). Closing the feedback loop: Ensuring effective action from student feedback. Tertiary Education \& Management, 9(2), 145-157.

[17] Makondo, L., \& Ndebele, C. (2014). University Lecturers' Views on Student-Lecturer Evaluations. Anthropologist, 17(2), 377-386.

[18] University of Fort Hare's policy on teaching and learning. University of Fort Hare, (2008). Evaluation of Teaching and Course Policy http://www.ufh.ac.za/tlc/sites/default/files/EvaluationofTeachingandCou rsePolicyreview.pdf (retrieved on 11/10/2015)

[19] Felder and Brent, R. (2009). Active learning. ASQ Higher Education Brief, 2(4), August 2009

[20] Gichinga, L. W., Mukulu, E., \& Mwachiro, S. (2014). Factors Determining Lecturers Perception of Student Evaluation of Teaching in Kenyan Universities. The International Journal of Humanities \& Social Studies. October 2014.

[21] Middendorf J, Pace, D. (2004). Decoding the Disciplines: A model for helping Students Learn Disciplinary ways of Thinking. New Directions for Teaching and Learning. 98:1-12.

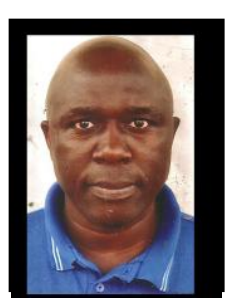

Professor Jabulani Ray Gumbo graduated with a PhD in Water Resources Management from University of Pretoria in 2007. He was awarded the second best student poster price at the $12^{\text {th }}$ International Conference on Harmful Algae in 2006 and the study was then published in the prestigious conference proceedings after a rigorous peer review process. This author became a Member (M) of International Society for the Study of Harmful Algae; International Mine Water Association; Water Institute of Southern Africa; Microscopy Society of Southern Africa and South African Council for Natural Scientific Professions. In 2008, he was appointed as a senior lecturer at University of Venda and in 2016 he was appointed as Associate Professor. He is the first or second author of more than 47 peer reviewed papers, conference proceedings and co-authored a chapter in a book. $\mathrm{He}$ acts as a reviewer for NRF in the fields of cyanobacteria and has been invited to be a reviewer for Ohio Sea Grant Proposal (USA); Journal of Applied Phycology (Australia); Bioresource Technology Journal (BITE) (USA); Journal of Freshwater Ecology (Britain); South African Journal of Science (SAJS) (South Africa) and African Journal of Biotechnology (AJB) (Nigeria). He lectures students at undergraduate and postgraduate levels in the fields of water treatment; water quality management; water law and institutions; rural water supply and sanitation; data information systems and water quality principles and he supervises several Honours, Masters and $\mathrm{PhD}$ students in the fields of water quality management; aquatic ecotoxicology and limnology and water treatment. In 2016 he and two other colleagues registered a patent on Defloridation of ground water rich in fluoride. 